\title{
Stakeholders' Responses to the COVID-19 Pandemic: A Blueprint for Health Crisis Communication
}

\author{
Lisa Bergson, Ed.D. \\ Bridgewater State University \\ Bridgewater, Massachusetts, USA \\ Thomasena Shaw, Ph.D. \\ Bridgewater State University \\ Bridgewater, Massachusetts, USA \\ Nancy Van Leuven, Ph.D. \\ California State University, Fresno \\ Fresno, California, USA
}

\begin{abstract}
In March of 2020, the COVID-19 pandemic changed everything. This qualitative phenomenological study of undergraduate communication students in a 4-year public university explored how as primary stakeholders for universities, students responded to the pandemic. Using Protective Action Decision Model (PADM), the researchers explored students' perceptions of the risk of contracting COVID-19 and the protective actions recommended, and how perceptions influenced protective action decision making and behavioral responses. This study fills a gap in the crisis communication literature by focusing on stakeholder perspectives rather than the typical organizational responses to crises; it affirmed the sequential nature of PADM and suggests it should be expanded to include the sense of loss stakeholders experience during a health crisis. It also presents a blueprint for communicating with stakeholders during a health crisis.
\end{abstract}

Keywords - COVID-19 pandemic, Crisis Communication, Health Crisis, Protective Action Decision Model, Stakeholders.

SUGGESTED CITATION: Bergson, L., Shaw, T., \& Van Leuven, N. (2021). Stakeholders' responses to the COVID-19 pandemic: A blueprint for health crisis communication. Proceedings of the International Crisis and Risk Communication Conference, Volume 4 (pp. 37-40). Orlando Fl: Nicholson School of Communication and Media. https://doi.org/10.30658/icrcc.2021.09

\section{INTRODUCTION}

In December 2019, a new type of coronavirus, SARS-Cov-2, caused an outbreak of the disease (COVID-19) in Wuhan, China. The potentially fatal disease quickly became a pandemic, the severity of which has not been seen for over a century [1]. More than 30 million cases of COVID-19 have been confirmed in the United States and more than 550,000 people have died from the virus as of March 31, 2021 [2]. On March 10, 2020 in response to the coronavirus outbreak in Massachusetts, Governor Charlie Baker declared a state of emergency and placed the Commonwealth in lockdown. Fouryear state universities moved to a fully online educational delivery model, a response that is still in place for the spring 2021 semester. To protect students and minimize community spread, campuses significantly reduced the number of students in dormitories, and classes are offered via Zoom or MS Teams. The pandemic essentially changed everything.

The vast majority of crisis communication and crisis management research is organization-centric and focuses on an organization's response strategies, image repair, restoring reputation and minimizing negative publicity [3]. Crisis communication literature lacks stakeholder perspectives that focus on public-driven research that find solutions for stakeholders and does not explore organizational crisis responses [4]. This study seeks to fill this gap in the literature by exploring how students responded to the many challenges presented by the pandemic. Due to the novel nature of the 
current global health crisis, there is scant data on stakeholder responses to the pandemic. This research explores what motivated students to take protective action, and provides a blueprint for organizations, specifically universities, on how to communicate with key stakeholders during a health crisis. the importance of their time investment. Take the time to explain the structure and preview the paper.

\section{LITERATURE REVIEW}

\section{GENERATION ZERS}

Traditional undergraduate college students are between the ages of 18-22. The Pew Research Center [5] refers to anyone born between 1996 and 2012 as Generation Z and suggests this group is even more diverse than the Millennials that immediately preceded them. Popular and academic literature, the latter of which is highly debated, repeatedly contend that Generation Zers are selfish, self-absorbed, narcissistic and entitled [6]. Generation Zers' behaviors are rooted in a "search for truth," [7]. This group is comfortable with technology having grown up with it and can readily access and evaluate vast amounts of data on the internet [6].

\section{PROTECTIVE ACTION DECISION MODEL (PADM)}

Protective Action Decision Model (PADM) looks at how individuals are influenced to adopt protective actions in response to a hazard or disaster [8]. Although PADM has mainly been used to study responses to environmental hazards and disasters such as coastal flooding, city smog, storms such as Superstorm Sandy, product recall crises, and nuclear disasters, but it has also been applied to health crises such as the H7N9 Influenza outbreak rendering PADM an appropriate model to use for stakeholders' responses to the deadly COVID-19 pandemic.

A multistage model, PADM has sequential steps that illustrate the way individuals typically decide whether to adopt protective actions against hazards, disasters and other crises [8]. The first stage involves individuals getting social and environmental cues that warn about the hazard, disaster or crisis that elicits pre-decisional processes whereby individuals hear, pay attention to and comprehend these warning messages. The next stage is a perceptual one. In this stage, individuals develop perceptions of their risk, the protective actions available to them and the trustworthiness of sources or stakeholders. From there, individuals make decisions about the behavioral responses they will or will not take. These responses could include: 1) Information searches 2) protective responses they will adopt to protect them from the virus and 3) emotion-focused coping mechanisms. Lindell and Perry [8] suggest that individuals can also be influenced by unexpected impediments or facilitators which either prevent or help them, respectively, from enacting protective actions. A feedback loop represents the last stage of the PADM model. This feedback loop is commonly used when people want to confirm or reject any warnings often by accessing a different source for information. It can also be used to obtain additional information about the hazard, disaster or crisis, which protective action to use and how to enact a chosen protective action [8].

This study explores one overarching research question: What are the perceptions and experiences of students, one of the university's main stakeholder groups, about their behavioral responses to the COVID-19 pandemic?

\section{METHODS}

This phenomenological IRB-approved study described the lived experiences of eight communication studies students (4 males, 4 females) at a four-year public university in the Northeast. An open-ended research question strategy lent itself to a qualitative research method with an exploratory design where the goal was to explore a phenomenon - the COVID-19 pandemic - which allowed participants to express multiple realities. The researchers followed the six research activities described by Van Manen [9] for hermeneutical phenomenological studies by: 1. Focusing on the lived experience by choosing a phenomenon - the COVID-19 pandemic - to identify perceptions, experiences and behavioral responses of students, one of the university's main stakeholder groups; 2. Investigating the experience of the participants' lived experiences through in-depth interviews; 3. Seeking the overall meaning of participant's experiences when reflecting on the emergent themes by reading each interview transcript for major themes and areas of convergence and divergence; 4. Writing and re-writing to ensure the participants' perceptions and experiences were accurately depicted; 5. Remaining focused on the research question to maintain a strong relation to the phenomenon; and 6. Continually moving between transcripts and themes in relation to behavioral responses to the COVID-19 pandemic to consider the whole in its entirety and the parts.

This study employed a purposeful sampling strategy. Using a snowball sample, the researchers identified the first participant who was a communication studies student over the age of 18 who had experienced the phenomenon being studied. That participant referred other communication studies students who experienced the phenomenon. This process continued until eight participants consented to participate in this study.

Researchers conducted 45-minute in-depth interviews via Zoom with participants, which were recorded (audio file only), transcribed verbatim and stored in a password-protected computer accessible only to the researchers. Participants' names were replaced with a number identifier (e.g., Student 1). Researchers reviewed the transcripts using inductive and deductive methods to search for major themes of convergence and divergence in and across cases. To ensure the 
trustworthiness of this study, one researcher coded the data and the co-researchers, both experienced colleagues, reviewed the coded data for accuracy, trustworthiness and to ensure there was no bias present.

\section{RESULTS}

Participants went through the sequential process outlined by PADM. Initially, when students heard about the coronavirus, they thought it was "no big deal," "just like the flu, happening "over there" and would be over soon. They soon realized 'this is real.'

\section{(DIS)TRUSTED SOURCES}

When it came to sources, participants trusted the SCIENCE. The CDC, FDA, Dr. Fauci, vaccine developers, and published scientific studies were viewed as most trusted and having the most expertise. They also highly trusted the university but perceived it had low expertise when it came to the virus. They distrusted "skewed" news coverage and social media, although they frequently used both.

"I trust the science. The sources I trust most would be the FDA, the CDC, and Dr. Fauci and Pfizer, and Johnson and Johnson, and the people who have done the extensive research on COVID-19." - Student 7

"I watch the news, but I do some fact checking with the CDC's website... This is what the news is saying. How much of this is really the truth or is it theater?" - Student 3

\section{NEW NORMAL: PROTECTIVE ACTIONS}

Participants' protective responses included using masks, hand sanitizer, washing hands, small social bubbles, and staying home whenever possible. They worried they would be stuck in this "new normal" for years.

"It's been a year, so I am kind of use to this lifestyle now... It is a new normal. You go out and you get your keys and your mask and it's just a daily routine.... It is sad to say that I've gotten used to the way we're living now, but that is the reality, and I am trying to make the best of it" - Student 4

\section{OTHERS ORIENTATION}

All participants believed their risk was high to very high, but they were most concerned about infecting others:

"I don't want to get it because I know it's unpredictable and even young and healthy people can still get affected, but I'm more concerned about giving it to someone else." - Student 6

\section{SENSE OF LOSS}

The pandemic has had unintended impacts. Participants expressed a sense of loss and coupled with isolation, fear and anxiety, their mental health suffered. To cope they engaged in emotion-focused mechanisms such as yoga, meditation, outdoor activities, and streaming videos.

"I just want my life as a 21-year-old back. I missed that whole year of my life. So, like, now I'm 22 and I'm afraid I am going to be stuck in this for the rest of my twenties." - Student 2

\section{UNIVERSITY'S CRISIS COMMUNICATION}

All participants thought the university did a very good job communicating during the crisis. They felt it had clear, consistent messaging, which eased their fears and anxieties.

"I think the university has done a pretty good job in terms of communicating. There are emails every so often from the university explaining these are health and safety tips, here are the rules for masks. And, they also have a website tab on the school's website with updated information on the pandemic." - Student 3

\section{DISCUSSION}

This study confirmed the sequential nature of PADM [8]. All participants went through the stages by attending to environmental and social cues, determining their perceived risks, making informed decisions about protective actions and finally adopting protective actions to keep themselves, their family members, and their personal social bubbles safe.

Contrary to popular and academic literature that repeatedly contends that Generation Zers are selfish, self-absorbed, narcissistic and entitled [7], this study found participants were more concerned with others than themselves. Participants possessed a surprising "others" orientation, showing great concern about possibly infecting others, especially elderly family members and immunocompromised friends. All participants adopted protective actions, not only to protect themselves from contracting COVID-19, but, more importantly, to prevent others from contracting the deadly disease. They maintained small social bubbles to limit their exposure to the coronavirus and minimize the chance that they would spread the disease. They sought out scientific and governmental trusted sources and fact-checked distrusted sources like the news and social media. Additionally, the constant communication from the university led all participants to express that the university did a good job with crisis communication during this pandemic. 
Unexpectedly, all participants expressed a significant sense of loss caused by the pandemic. The researchers suggest that PADM should be extended for health crises to include a sense of loss. This sense of loss coupled with stress, fear, anxiety and isolation caused by the pandemic negatively affected their mental health. As a result, participants sought out emotion-focused coping mechanisms such as yoga, meditation, and prayer to help them get to a "better place."

\section{CONCLUSION}

In conclusion, this study fills a gap in the literature and affirms PADM's sequential nature; however, the researchers extend the literature by suggesting that feelings of loss associated with changes brought about by the pandemic should be added to the model. If organizations fail to communicate with stakeholders about the grief or sense of loss they may experience during a health crisis, stakeholders may struggle or "suffer in silence." The researchers recommend creating connections among stakeholders to combat feelings of isolation, enlisting stakeholders to share testimonials, and disseminating mental health resources.

Although the findings of this study cannot be generalized to a broader audience, they are still useful for practice. The researchers have developed a blueprint on how to communicate with stakeholders during a health crisis.

\section{Author Biography}

Lisa Bergson, Ed.D., is an Assistant Professor of Public Relations at Bridgewater State University in Bridgewater, Massachusetts. She earned her Doctor of Education in Organizational Leadership from Northeastern University.

Thomasena Shaw, Ph.D., is an Associate Professor of Public Relations at Bridgewater State University in Bridgewater, Massachusetts. She earned her Ph.D. in Mass Communication from the University of Tennessee, Knoxville.

Nancy Van Leuven, Ph.D. is an Assistant Professor of Media, Communications and Journalism at California State University, Fresno. She earned her Ph.D. from the University of Washington.

\section{REFERENCES}

[1] Su, Z., McDonnell, D., Wen, J., Kozak, M., Abbas, J., Segalo, S., Li. X., Ahmad, J., Cheshmehzangi, A., Cai, Y., Yang, L., Xiang, Y. (2021). Mental health consequences of COVID-19 media coverage: the need for effective crisis communication practices. Globalization and Health, 17(4). https://doi.org/10.1186/s12992-020-00654-4

[2] John Hopkins University of Medicine. (2021, March 30). Coronavirus Resource Center. https://coronavirus.jhu.edu/map.html

[3] Cheng, Y., \& Shen, H. (2020). United Airlines crisis from the stakeholder perspective: Exploring customers' ethical judgment, trust, and distrust, and behavioral intentions. Public Relations Review, 46(2). https://doi.org/10.1016/j.pubrev.2020.101908

[4] Liu, B. F., \& Viens, J. (2020). Crisis and risk communication scholarship of the future: Reflections on research gaps. Journal of International Crisis and Risk Communication Research, 3(1), 7-14. https://doi.org/10.30658/jicrcr.3.1.1

[5] Dimock, M. (2019, Jan. 17). Defining generation. Where millennials and generation z begins. Pew Research Center. Retrieved from https://www.pewresearch.org/fact-tank/2019/01/17/where-millennials-end-and-generation-z-begins

[6] Grubbs, J. B., Exline, J. J., McCain, J., Campbell, W. K., Twenge, J. M. (2019). Emerging adult reactions to labeling regarding age-group differences in narcissism and entitlement. Plos One, 14(5): e0215637. https://doi.org/10.1371/journal.pone.0215637

[7] Francis, T., \& Hoefel, F. (2018). 'True Gen': Generation Z and its implications for companies. McKinsey \& Company. Retrieved from https://www.mckinsey.com/industries/consumer-packaged-goods/our-insights/true-gen-generation-z-and-its-implications-forcompanies

[8] Lindell, M. K., \& Perry, R. W. (2012). The protective action decision model: Theoretical modification and additional evidence. Risk Analysis, 32(4), 616-632. https://doi.org/10.1111/j.1539-6924.2011.01647.x

[9] Van Manen, M. (2016). Phenomenology of practice: Meaning-giving methods in phenomenological research and writing. New York, NY: Routledge 